\title{
Elevated intraocular pressure in patients with acromegaly
}

\author{
Luciano Quaranta • Ivano Riva • Gherardo Mazziotti • \\ Teresa Porcelli • Irene Floriani • Andreas Katsanos • \\ Andrea Giustina • Anastasios G. P. Konstas
}

Received: 22 December 2013 /Revised: 7 April 2014 / Accepted: 13 April 2014 /Published online: 10 May 2014

(C) Springer-Verlag Berlin Heidelberg 2014

\begin{abstract}
Purpose To evaluate central corneal thickness (CCT) and intraocular pressure (IOP) in a cohort of acromegalic patients, and to correlate CCT with serum levels of growth hormone (GH) and insulin-like growth factor 1 (IGF-1).

Methods Consecutive patients affected by acromegaly underwent a comprehensive endocrinological and ophthalmological evaluation, including serum GH and IGF-1 levels, CCT measured with ultrasonic pachymetry and IOP assessed with Goldmann applanation tonometry.

Results Fourteen patients with acromegaly and 28 healthy controls were included in the study. Acromegalic patients had a statistically higher median CCT $(570 \mu \mathrm{m}$ [range 551.5-638] vs 542.7 $\mu \mathrm{m}$ [range 461.5-610]; $p<0.01)$ and higher median IOP $(17.2 \mathrm{~mm} \mathrm{Hg}$ [range 14-21] vs $13.7 \mathrm{~mm}$
\end{abstract}

\footnotetext{
L. Quaranta $\cdot$ I. Riva

Department of Medical and Surgical Specialties, Radiological

Sciences and Public Health, University of Brescia, Brescia, Italy

G. Mazziotti · T. Porcelli • A. Giustina

Department of Clinical and Experimental Sciences, University of Brescia, Brescia, Italy

I. Floriani

IRCCS - Istituto di Ricerche Farmacologiche Mario Negri, Milano, Italy
}

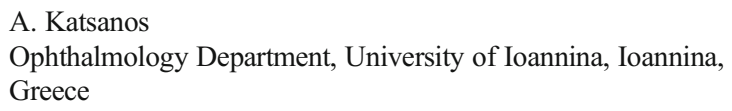

\section{A. G. P. Konstas}

Glaucoma Unit, Department of Ophthalmology, 1st University, AHEPA Hospital, Thessaloniki, Greece

L. Quaranta $(\bowtie)$

USVD "Centro per lo Studio del Glaucoma”, Piazzale Spedali Civili

1, 25123 Brescia, Italy

e-mail: luciano.quaranta@unibs.it
Hg [range 10.5-19]; $p<0.01$ ) than healthy controls. No statistically significant correlation was found among $\mathrm{CCT}$ and $\mathrm{GH}$, CCT and IGF-1, IOP and GH, IOP and IGF-1 in the acromegalic group, whereas a statistically significant correlation was documented between CCT and IOP in the entire cohort (Spearman's correlation coefficient: $0.56, p<0.01$ ). However, when IOP was corrected for CCT no significant difference was found between the two study groups ( $p=0.07$ ).

Conclusions Our results suggest that acromegaly is associated with an increased CCT, which could lead to an overestimation of IOP readings as determined with Goldmann applanation tonometry.

Keywords Acromegal · Central corneal thickness · Intraocular pressure $\cdot$ Glaucoma $\cdot$ Goldmann applanation tonometry

\section{Introduction}

Acromegaly is a rare condition usually caused by a growth hormone (GH)-secreting pituitary adenoma. It is characterized by excessive growth of the peripheral parts of the body and the occurrence of chronic complications which may cause impairment of quality of life and increased mortality [1-4]. Frequent ocular manifestations of acromegaly include visual field defects secondary to chiasmal compression by a pituitary adenoma, as well as proptosis, restrictive extraocular myopathy with diplopia or eyelid edema, and ptosis due to orbital soft tissue involvement $[5,6]$.

The presence of ocular abnormalities in children with pituitary-induced GH excess or deficiency suggests that GH plays a key role in eye development and growth during childhood [7, 8]. Moreover, patients with Laron syndrome, a primary GH receptor insensitivity, who are treated with insulin-like growth factor 1 (IGF-1) tend to have ocular 
dimensions that resemble the dimensions of healthy controls; on the contrary, untreated patients tend to have smaller ocular dimensions [9].

Elevated intraocular pressure (IOP) has been previously reported in patients with acromegaly [10-12]. A study by Greco and coworkers [13] showed that, after intravenous injection of arginine, patients with primary open-angle glaucoma (POAG) exhibited higher GH levels than healthy controls, thus suggesting a possible relationship between GH secretion and POAG. Further, other reports have demonstrated higher values of central corneal thickness (CCT) in acromegalic patients than in healthy subjects $[12,14,15]$.

It is now widely accepted that in a structurally normal cornea, higher CCT values may lead to an overestimation of IOP. A number of studies have therefore investigated the effect of CCT on Goldmann applanation tonometry (GAT), the gold standard technique for clinical IOP assessment [16-20]. Further, there is emerging evidence that CCT might be a useful tool for identifying patients at a greater risk of glaucoma progression and more susceptible to IOP-lowering medications [21, 22].

The aim of the present study was to evaluate CCT and IOP specifically in a cohort of consecutive acromegalic patients, and to ascertain whether there is a correlation between CCT and serum levels of GH and IGF-1.

\section{Materials and methods}

This was an observational, case-control study carried out at the Glaucoma Service of the University of Brescia, Brescia, Italy, with patients referred to the Endocrine Service of the Spedali Civili di Brescia, Brescia, Italy. The research protocol adhered to the tenets of the Declaration of Helsinki.

\section{Participants}

Consecutive patients with a confirmed clinical diagnosis of acromegaly who were under regular clinical follow-up were enrolled. The diagnosis of acromegaly relied upon evidence of failure of serum GH suppression to concentrations below $1 \mathrm{ng} / \mathrm{ml}$ after a $75-\mathrm{g}$ oral glucose load together with fasting plasma IGF-1 concentrations above the normal ranges for age [23]. Patients receiving somatostatin analogue treatment were evaluated by measurement of serum random GH and IGF-1, whereas those treated with pegvisomant were evaluated by serum IGF-1 alone [24]. Acromegaly was considered wellcontrolled if IGF-1 values were in the reference range for the patient's age. In patients receiving somatostatin analogues, acromegaly was considered well-controlled if random $\mathrm{GH}$ levels were below $1.0 \mathrm{ng} / \mathrm{ml} \mathrm{[24].} \mathrm{Median} \mathrm{duration} \mathrm{of} \mathrm{active}$ disease was estimated on the basis of clinical history. The duration of uncontrolled disease during medical treatment was also recorded.

The control group included healthy subjects, matched for sex and age, recruited from routine visits to the ophthalmology outpatient service. Exclusion criteria for eye conditions were: previous diagnosis of glaucoma or ocular hypertension, Snellen best-corrected visual acuity less than 0.4 , corneal or other ocular conditions making applanation tonometry unreliable, signs or history of ocular diseases, and previous ocular surgeries including cataract extraction or refractive surgery. Patients were also excluded if they were using systemic or topical steroids, or other drugs that could influence IOP levels.

\section{Assessments}

Serum GH and IGF-1 levels were collected from the patients' clinical charts: the mean of the last three measurements was used for the analysis. GH and IGF-1 were measured with Immulite 2000 (DPC, Los Angeles, CA, USA). For IGF-1, normal ranges were $136-244 \mathrm{ng} / \mathrm{ml}, 107-181 \mathrm{ng} / \mathrm{ml}$ and $97-$ $159 \mathrm{ng} / \mathrm{ml}$ for patients aged 20-39 years, $40-59$ years, and 60-79 years respectively.

All participants underwent a comprehensive ophthalmological evaluation that included visual acuity, anterior segment biomicroscopy, and fundus examination. After topical anesthesia with lidocaine $4 \%$ (Alpha Intes, Casoria, Italy), CCT was measured by means of an ultrasonic pachymeter (DGH500, DGH Technology Inc., Exton, PA, USA) and, immediately afterwards, IOP was assessed with GAT (Haag-Streit, Bern, Switzerland) after a fluoresceincontaining paper strip was lightly stroked at the inferior conjunctival fornix. The mean value of five CCT measurements was calculated. Two IOP readings were acquired at $10.00 \mathrm{AM}$ $\pm 1 \mathrm{~h}$; if the two readings differed by $>2 \mathrm{mmHg}$, a third measurement was obtained, and the mean value of the closest two readings was used. All CCT and IOP measurements were done by the same experienced ophthalmologist (IR). Both eyes of each participant were measured, but only one randomly selected eye was analyzed.

The formula suggested by Doughty and Zaman was used for the correction of IOP based on CCT values for both groups [18]. This formula assumes a correction of $2.5 \mathrm{mmHg}$ per $50 \mu \mathrm{m}$ of CCT deviation from $535 \mu \mathrm{m}$ and was derived with a meta-analysis approach from hundreds of CCT datasets published in the literature over the period from 1968 through mid1999.

\section{Statistics}

Categorical variables were reported as absolute and relative frequency, and differences between groups were tested by means of a Chi-square test. Continuous variables, such as $\mathrm{CCT}$ and IOP, were described using median, minimum and 
Table 1 Characteristics of the study population

\begin{tabular}{llll}
\hline & $\begin{array}{l}\text { Acromegalic patients } \\
(n=14) \text { : no. }(\%)\end{array}$ & $\begin{array}{l}\text { Control group } \\
(n=28): \text { no. }(\%)\end{array}$ & $P$-value \\
\hline Men & $7(50)$ & $12(42.8)$ & $0.74^{\dagger}$ \\
Women & $7(50)$ & $16(57.1)$ & \\
& Median (range) & Median (range) & $P$-value \\
Age (years) & $59.0(40-71)$ & $58.5(46-72)$ & $0.48^{*}$ \\
Duration of the disease (years) & $5(1-15)$ & - & - \\
GH $(\mathrm{ng} / \mathrm{ml})$ & $0.9(0.01-22)$ & - & - \\
IGF-1 $(\mathrm{ng} / \mathrm{ml})$ & $173.5(48-513)$ & - & - \\
IOP $(\mathrm{mm} \mathrm{Hg})$ & $17.2(14-21)$ & $13.7(10.5-19)$ & $<0.01^{*}$ \\
Corrected IOP $(\mathrm{mm} \mathrm{Hg})^{\ddagger}$ & $14.8(11.9-20.1)$ & $13.9(10.3-18.6)$ & $0.07^{*}$ \\
CCT $(\mu \mathrm{m})$ & $570(551.5-638)$ & $542.7(461.5-610)$ & $<0.01^{*}$ \\
\hline
\end{tabular}

maximum values and were tested for normal distribution by means of a Shapiro-Wilk test. A Mann-Whitney $U$ test was used to compare continuous variables between groups. Correlations among IOP, CCT, GH, and IGF-1 were evaluated using the Spearman's correlation coefficient. Level of significance was set at 0.05 , for a bilateral test. The analyses were made using SAS software (Statistical Analysis System, version 9.4; SAS Institute Inc., Cary, NC, USA).

\section{Results}

During the course of the study 14 consecutive patients with acromegaly and 28 age and sex-matched controls were enrolled. All participants were Caucasian. Table 1 shows the characteristics of the two cohorts.

Eleven of the 14 acromegalic patients had already been treated with neurosurgery, and all of them required further treatment (somatostatin analogues and/or pegvisomant) for the persistence of GH hypersecretion [25]. Two patients were treated with somatostatin analogues as first-line therapy. At the time of the study, 12 patients had controlled disease, whereas the remaining two patients had active acromegaly notwithstanding different treatments regimens [24]. Median duration of active disease was 5 years (range: 1-15).

The CCT and IOP values recorded in acromegalic patients were significantly greater than those documented in the controls (Table $1 ; p<0.01$ ). However, when IOP was corrected for CCT [18], no statistically significant difference was detected between the two groups (Table $1 ; p=0.07$ ). Moreover, no significant correlation could be documented between CCT and GH, CCT and IGF-1, IOP and GH, IOP and IGF-1 in the acromegalic group (Table 2, Fig. 1 and Fig. 2), whereas a statistically significant correlation was observed between CCT and IOP when the entire cohort was considered (Spearman's coefficient: 0.56; $p<0.01$; Table 2, Fig. 3).

\section{Discussion}

Our results suggest that acromegaly may be associated with an increased CCT, and acromegalic patients appear to have higher IOP values than normal controls. It is well-known that CCT and other corneal parameters influence GAT readings because IOP is calculated assuming a fixed CCT of $520 \mu \mathrm{m}$, disregarding inter-individual variability [26]. Consequently, GAT underestimates IOP in patients with a thin cornea, and overestimates it in those with a thick cornea. A review of the literature showed corneal thickness-related deviations in GAT measurements ranging from 0.11 to $0.71 \mathrm{mmHg}$ for every $10 \mu \mathrm{m}$ change in CCT $[16,17]$.

Published evidence to date has indicated that IOP is significantly increased in acromegalic patients when compared with healthy subjects [12, 14, 27]. Consequently, acromegaly has been considered a risk factor for glaucoma development [10, 11]. Polat and coworkers [15] found that acromegaly was associated with higher levels of IOP, but contrary to our results did not detect a significant difference in the CCT of patients with acromegaly compared to controls. The difference with our data may be attributed to the extreme range of CCT for

Table 2 Spearman's correlation coefficients for tested variables

\begin{tabular}{lllll}
\hline Correlation & Group & $N$ & Spearman $\rho$ & $P$-value \\
\hline CCT - IOP & Entire cohort & 42 & 0.56 & $<0.01$ \\
& Acromegalic patients & 14 & 0.07 & 0.8 \\
& Healthy subjects & 28 & 0.44 & 0.01 \\
CCT - GH & Acromegalic patients & 14 & -0.43 & 0.14 \\
CCT - IGF-1 & Acromegalic patients & 14 & 0.23 & 0.42 \\
IOP - GH & Acromegalic patients & 14 & 0.08 & 0.78 \\
IOP - IGF-1 & Acromegalic patients & 14 & 0.21 & 0.47 \\
\hline
\end{tabular}

$C C T$ central corneal thickness, IOP intraocular pressure, $G H$ growth hormone, $I G F-1$ insulin-like growth factor 1 
Fig. 1 Scatter-plot of central corneal thickness vs. growth hormone serum levels for acromegalic patients

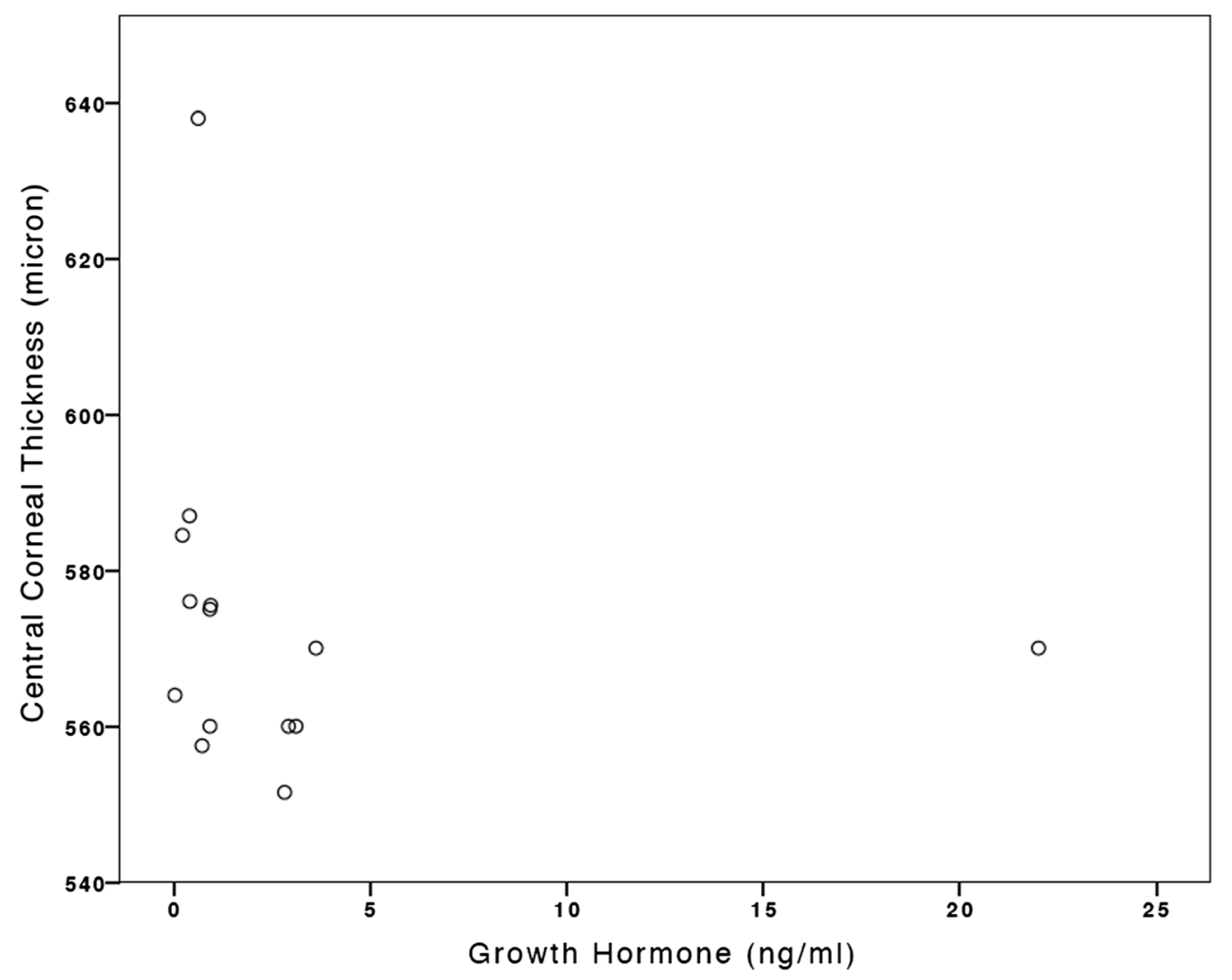

normal eyes reported in that study (right eye CCT range: 274 $643 \mu \mathrm{m}$, left eye CCT range: $267-643 \mu \mathrm{m})$. In a recent study using the Ocular Response Analyzer, Ozkok et al. [28] reported that patients with acromegaly had significantly different

Fig. 2 Scatter-plot of intraocular pressure vs. growth hormone serum levels for acromegalic patients

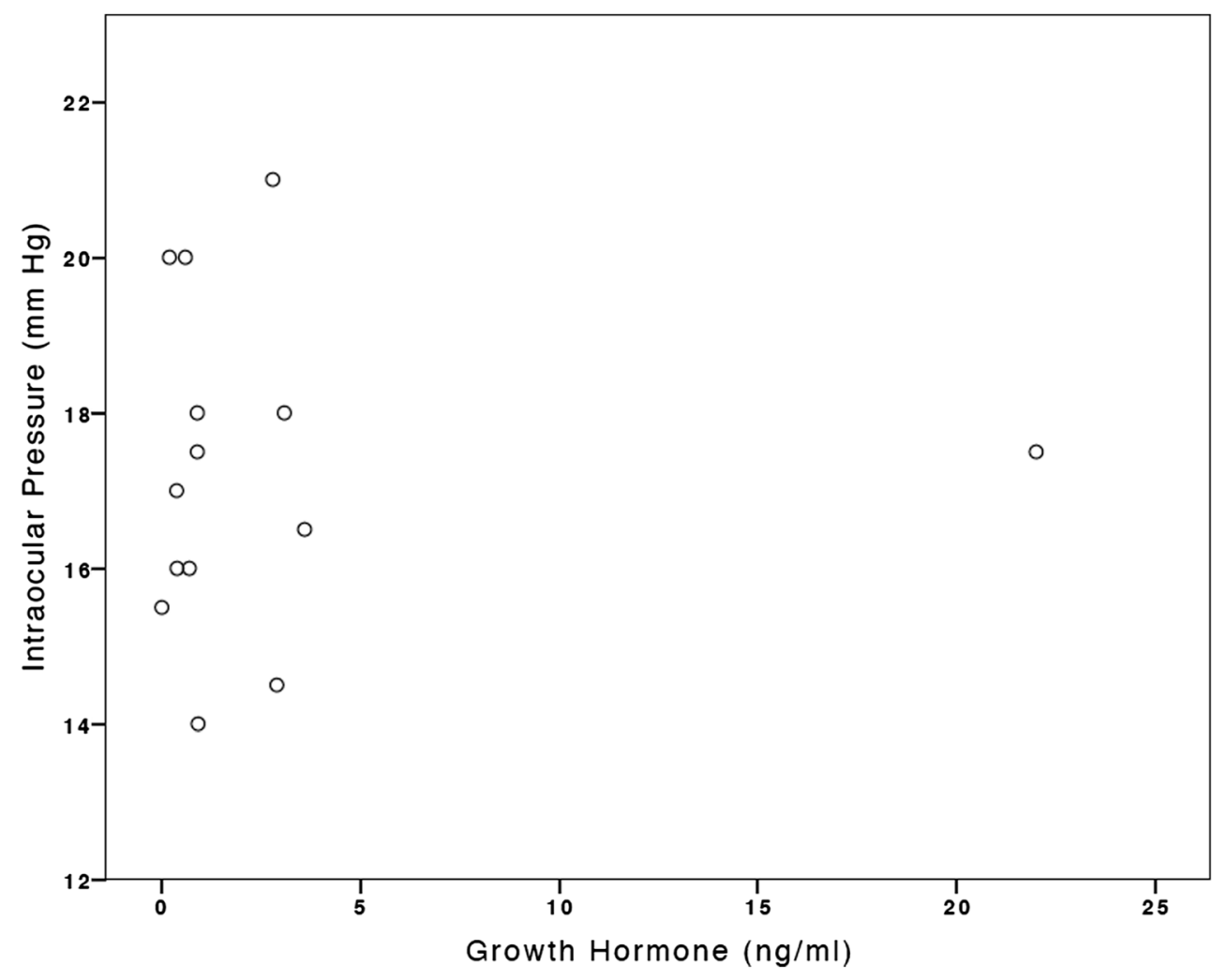


Fig. 3 Scatter-plot of central corneal thickness vs. intraocular pressure for the entire cohort of the study

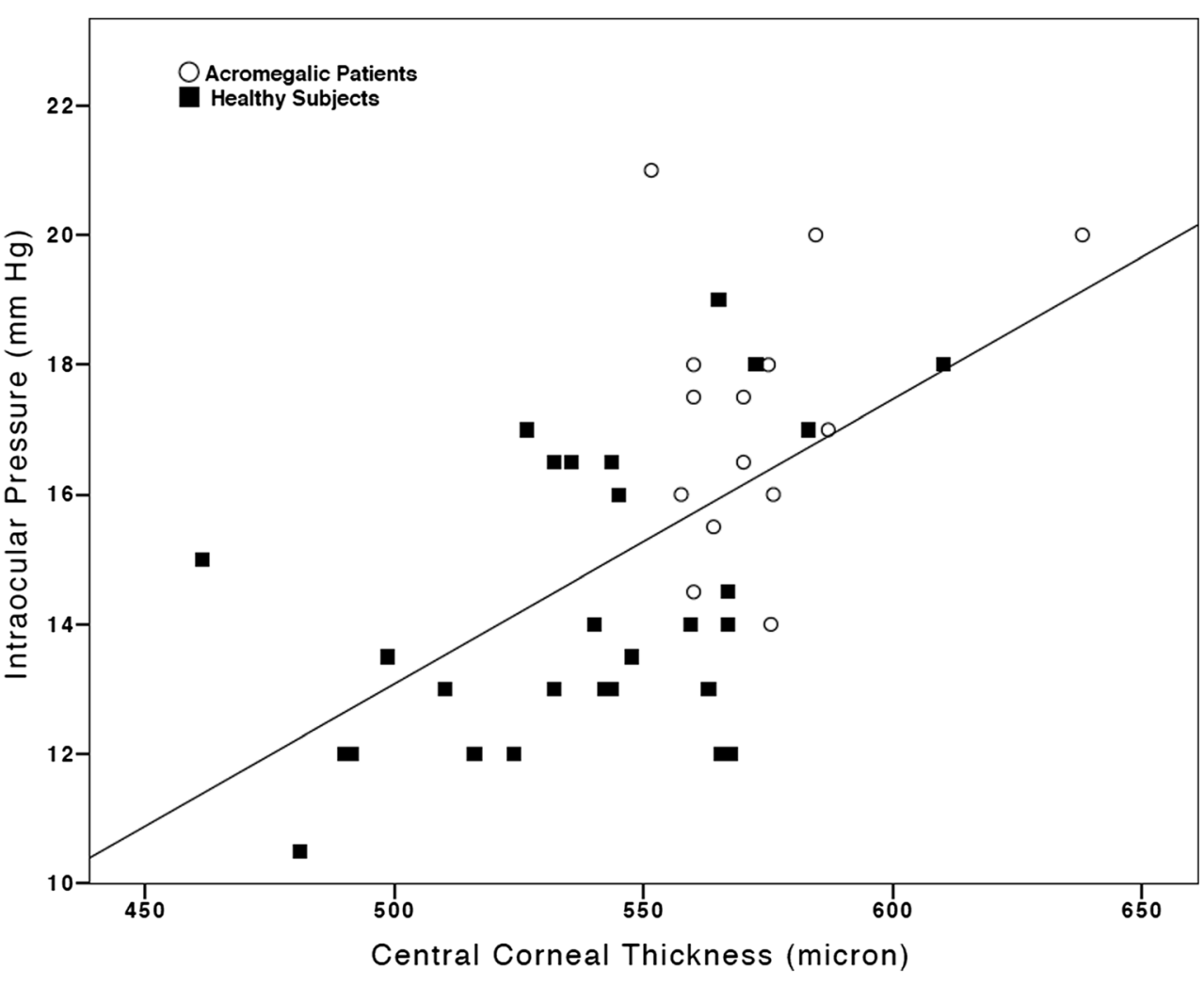

corneal biomechanical properties compared to age- and sexmatched controls. Specifically, the authors found that acromegalic patients had higher corneal hysteresis and corneal resistance factor compared to controls. Although Goldmannequivalent readings were higher in the patient group, neither CCT nor CCT-compensated IOP readings were significantly different between the two groups. Consequently, in this cohort, the apparent differences in Goldmann-equivalent readings could be attributed to acromegaly-induced corneal biomechanical changes. On the other hand, our data suggest that the higher GAT readings observed in patients with acromegaly are due to an increased CCT and do not represent an actual
IOP elevation. This is supported by the fact that when IOP was corrected for CCT according to the formula proposed by Doughty and Zaman [18], no significant IOP difference could be detected between acromegalic and healthy subjects. Our results corroborate findings by Bramsen et al. [12]. The authors investigated GAT readings and CTT measurements obtained with optical pachymetry in patients with pituitary tumors with $(n=13)$ and without acromegaly $(n=14)$. They found that both CCT and GAT readings were higher in acromegalic patients, but the CCT-corrected IOP readings were similar in the two groups. Although not explicitly stated by Bramsen et al. [12], it seems that they used the correction

Table 3 Summary of previous studies about CCT and IOP in patients affected by acromegaly in comparison with controls

\begin{tabular}{|c|c|c|c|c|c|c|}
\hline & \multicolumn{3}{|c|}{ Patients affected by acromegaly } & \multicolumn{3}{|l|}{ Controls } \\
\hline & $N$ & $\mathrm{CCT}($ mean $\pm \mathrm{SD}, \mu \mathrm{m})$ & $\begin{array}{l}\mathrm{IOP}(\text { mean } \pm \mathrm{SD} \\
\mathrm{mm} \mathrm{Hg})\end{array}$ & $N$ & $\mathrm{CCT}($ mean $\pm \mathrm{SD}, \mu \mathrm{m})$ & $\begin{array}{l}\mathrm{IOP}(\text { mean } \pm \mathrm{SD} \\
\mathrm{mm} \mathrm{Hg})\end{array}$ \\
\hline Bramsen et al. (1980) [12] & 13 patients & $561 \pm 35$ & $16.9 \pm 2.3$ & 14 subjects & $526 \pm 30$ & $14.7 \pm 2.4$ \\
\hline Ciresi et al. (2011) [14] & 28 patients & $567(559-573.5)^{*}$ & $19(18-21)^{*}$ & 22 subjects & $528.5(517-535)^{*}$ & $17(16.5-18)^{*}$ \\
\hline Polat et al. (2013) [15] & 30 patients & $529.2(471-630)+$ & $16(11-19)+$ & 21 subjects & $537(487-643)+$ & $13(9-20) \ddagger$ \\
\hline \multirow[t]{2}{*}{ Ozkok et al. (2014) [28] } & 46 right eye & $545.4 \pm 29.2$ & $17.1 \pm 4.2 \dagger$ & 42 right eye & $555.1 \pm 28.4$ & $15.1 \pm 3.0 \dagger$ \\
\hline & 46 left eye & $545.8 \pm 31.6$ & $17.3 \pm 4.2 \dagger$ & 42 left eye & $557.5 \pm 27.1$ & $14.7 \pm 3.1 \dagger$ \\
\hline
\end{tabular}

$C C T$ central corneal thickness, IOP intraocular pressure, *median of the mean (interquartile range); $\ddagger$ : median of the mean (range) $\dagger:$ Ocular Response Analyzer Goldmann correlated intraocular pressure 
algorithm suggested by Ehlers et al. [16]. This algorithm assumes a different correction factor depending on the level of GAT reading and CCT value. On the other hand, we assumed a correction of $2.5 \mathrm{mmHg}$ per $50 \mu \mathrm{m}$ of CCT deviation from $535 \mu \mathrm{m}$ as suggested by Doughty and Zaman [18]. In their study, Bramsen et al. found that the mean CCTcorrected IOP in pituitary tumor patients with and without acromegaly was $14.1 \pm 2.3$ and $14.2 \pm 2.4 \mathrm{mmHg}$ respectively. These results closely match our data: the median CCTcorrected IOP of acromegalic patients and controls was 14.8 (range: 11.9-20.1) and 13.9 (range: $10.3-18.6) \mathrm{mmHg}$ respectively.

It is not entirely understood why acromegalic patients have thicker corneas than healthy subjects. Visceromegaly is a common clinical feature of acromegaly attributed to the growth-promoting chronic effect of the GH on many organs. The eye seems to be a target site for GH action, and GH may have endocrine, autocrine or paracrine roles in ocular development and growth. Thus, it is conceivable that corneal tissue is a target for GH action. It is noteworthy that Ciresi and coworkers [14] observed a strong linear correlation between CCT and GH levels in a group of 28 patients with acromegaly. Our study did not find a statistically significant correlation between CCT and GH plasma levels. This lack of correlation may be due to the small sample size and the inevitable data scatter. The relationship between $\mathrm{CCT}$ and GH requires further research in a larger cohort of patients with acromegaly. Confounding factors may include previous treatments (radiotherapy, medical, or surgical therapies) and lack of documented GH and IGF-1 plasma levels at diagnosis.

In common with previous reports, a limitation of the present study is the small sample size due to the rarity of the disease (Table 3). A potential bias of our study is related to the fact that most our patients were on treatment with somatostatin analogues which may have impacted ocular tissues regardless of control of GH hypersecretion, as already demonstrated for other clinical investigations [29-31]. Further controlled studies are needed to better delineate the impact of GH upon ocular tissues.

In conclusion, our data suggest that acromegaly is associated with increased CCT that could lead to an overestimation of IOP readings as determined by GAT and possibly future glaucoma development risk. Therefore, CCT evaluation should be considered an important component of the ophthalmic assessment in acromegalic patients.

\footnotetext{
Acknowledgments None

Conflict of interest None.
}

\section{References}

1. Melmed S (2006) Medical progress: Acromegaly. N Engl J Med 355(24):2558-2573. doi:10.1056/NEJMra062453

2. Giustina A, Casanueva FF, Cavagnini F, Chanson P, Clemmons D, Frohman LA, Gaillard R, Ho K, Jaquet P, Kleinberg DL, Lamberts SW, Lombardi G, Sheppard M, Strasburger CJ, Vance ML, Wass JA, Melmed S, Pituitary S (2003) The European Neuroendocrine: a diagnosis and treatment of acromegaly complications. J Endocrinol Investig 26(12):1242-1247

3. Melmed S, Casanueva FF, Klibanski A, Bronstein MD, Chanson P, Lamberts SW, Strasburger CJ, Wass JA, Giustina A (2013) A consensus on the diagnosis and treatment of acromegaly complications. Pituitary 16(3):294-302. doi:10.1007/s11102-012-0420-x

4. Mazziotti G, Bianchi A, Porcelli T, Mormando M, Maffezzoni F, Cristiano A, Giampietro A, De Marinis L, Giustina A (2013) Vertebral fractures in patients with acromegaly: a 3-year prospective study. J Clin Endocrinol Metab 98(8):3402-3410. doi:10.1210/jc. 2013-1460

5. Reid TJ, Post KD, Bruce JN, Nabi Kanibir M, Reyes-Vidal CM, Freda PU (2010) Features at diagnosis of 324 patients with acromegaly did not change from 1981 to 2006: acromegaly remains underrecognized and under-diagnosed. Clin Endocrinol 72(2):203-208. doi:10.1111/j.1365-2265.2009.03626.x

6. Heireman S, Delaey C, Claerhout I, Decock CE (2011) Restrictive extraocular myopathy: a presenting feature of acromegaly. Indian J Ophthalmol 59(6):517-519. doi:10.4103/0301-4738.86330

7. Parentin F, Pensiero S (2010) Central corneal thickness in children with growth hormone deficiency. Acta Ophthalmol (Copenh) 88(6): 692-694. doi:10.1111/j.1755-3768.2009.01519.x

8. Hellstrom A, Svensson E, Carlsson B, Niklasson A, AlbertssonWikland K (1999) Reduced retinal vascularization in children with growth hormone deficiency. J Clin Endocrinol Metab 84(2):795-798

9. Bourla DH, Laron Z, Snir M, Lilos P, Weinberger D, Axer-Siegel R (2006) Insulinlike growth factor I affects ocular development: a study of untreated and treated patients with Laron syndrome. Ophthalmology 113(7):1197.e1-1197.e5. doi:10.1016/j.ophtha. 2005.12.023

10. Howard GM, English FP (1965) Occurrence of glaucoma in acromegalics. Arch Ophthalmol 73:765-768

11. Aren A, Skanse B (1955) On non-inflammatory glaucoma in acromegaly. Acta Ophthalmol (Copenh) 33(3):295-306

12. Bramsen T, Klauber A, Bjerre P (1980) Central corneal thickness and intraocular tension in patients with acromegaly. Acta Ophthalmol (Copenh) 58(6):971-974

13. Greco AV, Ricci B, Altomonte L, Rebuzzi AG, Manna R, Ghirlanda G (1979) GH secretion in open-angle glaucoma. Ophthalmologica 179(3):168-172

14. Ciresi A, Amato MC, Morreale D, Lodato G, Galluzzo A, Giordano C (2011) Cornea in acromegalic patients as a possible target of growth hormone action. J Endocrinol Investig 34(2):e30-e35. doi: $10.3275 / 7205$

15. Polat SB, Ugurlu N, Ersoy R, Oguz O, Duru N, Cakir B (2013) Evaluation of central corneal and central retinal thicknesses and intraocular pressure in acromegaly patients. Pituitary [Epub ahead of print]. doi:10.1007/s11102-013-0505-1

16. Ehlers N, Bramsen T, Sperling S (1975) Applanation tonometry and central corneal thickness. Acta Ophthalmol (Copenh) 53(1):34-43

17. Herndon LW, Choudhri SA, Cox T, Damji KF, Shields MB, Allingham RR (1997) Central corneal thickness in normal, glaucomatous, and ocular hypertensive eyes. Arch Ophthalmol 115(9):1137-1141

18. Doughty MJ, Zaman ML (2000) Human corneal thickness and its impact on intraocular pressure measures: a review and meta-analysis approach. Surv Ophthalmol 44(5):367-408 
19. Wolfs RC, Klaver CC, Vingerling JR, Grobbee DE, Hofman A, de Jong PT (1997) Distribution of central corneal thickness and its association with intraocular pressure: the Rotterdam Study. Am J Ophthalmol 123(6):767-772

20. Argus WA (1995) Ocular hypertension and central corneal thickness. Ophthalmology 102(12):1810-1812

21. De Moraes CG, Juthani VJ, Liebmann JM, Teng CC, Tello C, Susanna R Jr, Ritch R (2011) Risk factors for visual field progression in treated glaucoma. Arch Ophthalmol 129(5):562-568. doi:10.1001/ archophthalmol.2011.72

22. Medeiros FA, Weinreb RN (2012) Is corneal thickness an independent risk factor for glaucoma? Ophthalmology 119(3):435-436. doi: 10.1016/j.ophtha.2012.01.018

23. Giustina A, Barkan A, Casanueva FF, Cavagnini F, Frohman L, Ho K, Veldhuis J, Wass J, Von Werder K, Melmed S (2000) Criteria for cure of acromegaly: a consensus statement. J Clin Endocrinol Metabol 85(2):526-529

24. Giustina A, Chanson P, Bronstein MD, Klibanski A, Lamberts S, Casanueva FF, Trainer P, Ghigo E, Ho K, Melmed S, Acromegaly Consensus G (2010) A consensus on criteria for cure of acromegaly. J Clin Endocrinol Metabol 95(7):3141-3148. doi:10.1210/jc.20092670

25. Melmed S, Colao A, Barkan A, Molitch M, Grossman AB, Kleinberg D, Clemmons D, Chanson P, Laws E, Schlechte J, Vance ML, Ho K, Giustina A, Acromegaly Consensus G (2009) Guidelines for acromegaly management: an update. J
Clin Endocrinol Metabol 94(5):1509-1517. doi:10.1210/jc. 2008-2421

26. Whitacre MM, Stein R (1993) Sources of error with use of Goldmann-type tonometers. Surv Ophthalmol 38(1):1-30

27. Youngster I, Rachmiel R, Pinhas-Hamiel O, Bistritzer T, Zuckerman-Levin N, de Vries L, Naugolny L, Eyal O, Braunstein R, Rachmiel M (2012) Treatment with recombinant human growth hormone during childhood is associated with increased intraocular pressure. J Pediatr 161(6):11161119. doi:10.1016/j.jpeds.2012.05.024

28. Ozkok A, Hatipoglu E, Tamcelik N, Balta B, Gundogdu AS, Ozdamar MA, Kadioglu P (2014) Corneal biomechanical properties of patients with acromegaly. Br J Ophthalmol 98(5):651-657. doi:10. 1136/bjophthalmol-2013-304277

29. Mazziotti G, Floriani I, Bonadonna S, Torri V, Chanson P, Giustina A (2009) Effects of somatostatin analogs on glucose homeostasis: a metaanalysis of acromegaly studies. J Clin Endocrinol Metabol 94(5):1500-1508. doi:10.1210/jc.2008-2332

30. Giustina A, Mazziotti G, Torri V, Spinello M, Floriani I, Melmed S (2012) Meta-analysis on the effects of octreotide on tumor mass in acromegaly. PLoS ONE 7(5):e36411. doi:10.1371/journal.pone. 0036411

31. Giustina A, Karamouzis I, Patelli I, Mazziotti G (2013) Octreotide for acromegaly treatment: a reappraisal. Expert Opin Pharmacother 14(17):2433-2447. doi:10.1517/14656566. 2013.847090 